\title{
THE EFFECT OF HEATING ACRYLIC RESIN OF VARIOUS TYPES WITH DIFFERENT TEMPERATURES ON IMPACT STRENGTH
}

\author{
Didik Marsigid $^{1 *}$, Handoko Tirta ${ }^{1}$, dan Tasrip ${ }^{1}$ \\ ${ }^{1}$ Jurusan Teknik Gigi, Poltekkes Jakarta II, Alamat, Jalan Hang Jebat III Blok F/3 Keb Baru \\ Jakarta Selatan 12120 \\ E-mail: didik.marsigid@gmail.com
}

Submitted: $8^{\text {th }}$ June 2021 ; Accepted: December $21^{\text {th }}, 2021$

https://doi.org/10.36525/sanitas.2021.13

\begin{abstract}
Resin polymerization which is affected by unstable temperature causes the resin to break easily. The strength of the base material is affected by the forces acting in the mouth, such as transverse forces, other resistance or fatigue, and flexibility. Fracture of denture caused by masticatory loads and is affected by forces acting in the mouth, including transverse, resistance or fatigue, and flexural forces. Experimental Laboratory total of 72 samples consisting of 18 samples of type $\mathrm{A}, \mathrm{B}$ and $\mathrm{C}$ cured at normal temperature, $100^{\circ} \mathrm{C}, 200^{\circ} \mathrm{C}$, and $300^{\circ} \mathrm{C}$. Types $\mathrm{A}, \mathrm{B}$ and $\mathrm{C}$ have the effect of heating with the addition of temperature on the impact strength of acrylic resin, because the value of sig = $0.001<0.05$, so $\mathrm{H} 0$ is rejected. An effect with the addition of temperature on the impact strength of the resin types $\mathrm{A}, \mathrm{B}$ and $\mathrm{C}$, because sig $=0.001<0.05$, so $\mathrm{H} 0$ is rejected, which means that the average results are significantly different due to differences in temperature.
\end{abstract}

Keywords: Acrylic resin heating, different temperatures, impact strength. 


\title{
PENGARUH PEMANASAN RESIN AKRILIK BERBAGAI TIPE DENGAN SUHU YANG BERBEDA TERHADAP IMPACT STRENGTH
}

\begin{abstract}
ABSTRAK
Polimerisasi resin yang dipengaruhi oleh suhu yang tidak stabil menyebabkan resin mudah pecah. Kekuatan bahan dasar dipengaruhi oleh gaya-gaya yang bekerja di dalam mulut, seperti gayagaya transversal, tahanan atau kelelahan lain, dan kelenturan. Fraktur gigi tiruan disebabkan oleh beban pengunyahan dan dipengaruhi oleh gaya-gaya yang bekerja di dalam mulut, antara lain gaya transversal, tahanan atau kelelahan, dan gaya lentur. Laboratorium eksperimen berjumlah 72 sampel yang masing-masing tipe sampel terdiri dari 18 sampel tipe $\mathrm{A}, \mathrm{B}$ dan $\mathrm{C}$ yang dimasak pada suhu normal, $100^{\circ} \mathrm{C}, 200^{\circ} \mathrm{C}$ dan $300^{\circ} \mathrm{C}$. Tipe $\mathrm{A}, \mathrm{B}$ dan $\mathrm{C}$ memiliki pengaruh pemanasan dengan penambahan suhu terhadap kekuatan impak resin akrilik, karena nilai dari sig $=0,001<$ 0,05, maka H0 ditolak. Efek dengan penambahan suhu pada kekuatan impak resin tipe A, B dan $\mathrm{C}$, karena sig $=0,001<0,05$ maka $\mathrm{H} 0$ ditolak yang berarti rata-rata hasil berbeda nyata karena perbedaan temperatur.
\end{abstract}

Kata kunci: Pemanasan resin akrilik, temperatur berbeda, kekuatan impak

\section{PENDAHULUAN}

World Health Organisation (WHO) dalam The World Oral Health Report menyatakan bahwa masyarakat Indonesia kurang menjaga kebersihan gigi dan mulut berakibat pada peningkatan prevalensi edentulousness yang mencapai $24 \%$ dengan rata-rata umur di atas 65 tahun dan sebagian penduduk Indonesia yang menderita gangguan kesehatan gigi dan mulut masih mencapai 90\%.(1)

Kehilangan gigi disebabkan oleh karies dan penyakit periodontal yang dipengaruhi beberapa faktor.(2) Dampaknya dapat mempengaruhi seseorang baik dari segi fungsional, estetika, dan sosial. Keadaan kehilangan gigi yang parah tentu akan sangat berdampak terhadap penurunan kualitas hidup seseorang dan juga mengganggu kelangsungan hidup mereka.(2)

Pemakaian gigi tiruan sebagai pengganti gigi yang hilang dalam hal perawatannya sangat penting.(4) Untuk mengembalikan fungsi dan estetis akibat kehilangan gigi dibutuhkan suatu gigi tiruan.(5) Gigi tiruan berfungsi untuk meningkatkan kemampuan dalam mengunyah, berbicara, memberikan dukungan untuk otot wajah, dan meningkatkan penampilan wajah dan senyum.(6) 
Tahun 1837 basis gigi tiruan ditemukan terbuat dari bahan vulkanit, kemudian tahun 1907 diperkenalkan bahan logam dan sejak tahun 1937 bahan basis gigi tiruan umumnya terbuat dari resin akrilik. Berdasarkan setting reaksinya, resin akrilik dibedakan menjadi resin akrilik polimerisasi kimiawi (auto curing), resin akrilik polimerisasi cahaya (light curing) dan resin akrilik polimerisasi panas (heat cured). $(7,8)$

Resin-resin tersebut merupakan plastik lentur yang dibentuk dengan menggabungkan molekul - molekul multiple metil metakrilat . Polimetil metakrilat murni adalah tidak berwarna, transparan dan padat. Untuk mempermudah penggunaannya dalam kedokteran gigi, polimer diwarnai untuk mendapatkan warna dan derajat kebeningannya.(8)

Jenis resin akrilik yang sering dipakai adalah polimerisasi panas karena memiliki beberapa keunggulan, yaitu memenuhi syarat estetik, stabilitas warna baik, tidak mengiritasi, tidak toksik, harga relatif murah, cara pengerjaannya mudah, pembuatan dan reparasi mudah. $(9,10)$ Resin akrilik heat cured merupakan campuran antara monomer metil metakrilat dan polimer polimetil metakrilat yang dipolimerisasi dengan cara pemanasan.(11)

Resin akrilik berpolimerisasi bila suhu dinaikkan melebihi $60^{\circ} \mathrm{C}$, molekul benzoil peroksida yang berperan sebagai inisiator akan terurai menjadi radikal bebas yang bereaksi dengan molekul monomer untuk membentuk radikal bebas yang baru dan seterusnya sehingga terjadi reaksi propagasi sampai terminasi. $(8,12,13)$ Selama pembuatan basis protesa, resin akrilik dipanaskan dengan merendam kuvet protesa ke dalam bak air atau waterbath proses tersebut dinamakan curing. Pemrosesan resin akrilik dapat dilakukan dengan cara pemanasan dalam air pada suhu $70^{\circ} \mathrm{C}$ selama 8 jam, atau dengan cara dipanaskan dalam air pada suhu 1 jam 30 menit kemudian suhu dinaikkan menjadi $100^{\circ} \mathrm{C}$ selama 1 jam. $(8,12,13)$ Teknisi gigi biasanya melakukan curing dengan cara pemanasan di kompor sehingga suhu yang dihasilkan tidak akurat.(12) Akibatnya basis gigi tiruan akan timbul banyak kekurangan seperti porus dan mudah patah. Polimerisasi resin akrilik adalah eksotermal, dan besarnya panas yng terlibat dapat mempengaruhi sifat basis protesa yang dibuat. $(8,13,14)$

Selain karena pengaruh suhu yang tidak stabil sehingga menyebabkan gigi tiruan mudah patah resin akrilik sendiri memang memiliki kekurangan pada sifat mekanik yaitu mudah fraktur bila jatuh pada permukaan yang keras atau akibat kelelahan bahan karena lama pemakaian. Fraktur atau patahnya gigi tiruan juga bisa disebabkan oleh beban mastikasi atau kekuatan bahan 
SANITAS: JURNAL TEKNOLOGI DAN SENI KESEHATAN

basis gigi tiruan. Kekuatan bahan basis gigi tiruan dipengaruhi oleh gaya-gaya yang bekerja di dalam mulut, diantaranya gaya transverse, impact atau fatigue resistance dan flexural.(7,8). Kekuatan impact merupakan kerusakan seketika atau fraktur basis gigi tiruan akibat dari satu pukulan yang keras, hal ini sering terjadi di luar mulut, dimana satu pukulan yang keras didapati pada saat basis gigi tiruan jatuh secara tiba-tiba ketika dibersihkan, atau bersin $(8,15)$

Berdasarkan uraian di atas, dapat dirumuskan sebagai berikut: "bagaimana pengaruh pemanasan resin akrilik dengan suhu yang berbeda terhadap impact strength?". Tujuan umum penelitian ini adalah untuk mengetahui pengaruh pemanasan resin akrilik dengan suhu yang berbeda terhadap impact strength .

\section{METODE PENELITIAN}

Metode penelitian dalam penelitian ini ialah dengan metode eksperimen laboratorium dengan cara pembuatan sampel balok akrilik yang dilakukan dengan bahan akrilik yang dipanaskan (heat cured) yaitu dengan pola malam/lilin yang dibuat dari mold cetakan kemudian ditanam dalam gips plaster of paris, kemudian langkah kedua dengan memanaskan air untuk metode curing dengan suhu masing - masing kelompok yaitu $100^{\circ} \mathrm{C}, 200^{\circ} \mathrm{C}, 300^{\circ} \mathrm{C}$, lalu masukkan kuvet yang akan di-curing sesuai dengan waktu aturan pabrik.

Semua sampel dilakukan pengambilan data dengan mengukur nilai impact strength-nya dengan cara mencatat dan mengamati profil data berupa grafik yang terlihat ada layar komputer uji impact strength.

\section{HASIL DAN PEMBAHASAN}

Bahan yang digunakan pada penelitian ini adalah resin akrilik, terdiri dari berbagai tipe yang berbeda-beda yaitu tipe A, B dan C (berbeda merk bahan akrilik). Spesimen yang digunakan berbentuk balok dengan perlakuan pemanasan pada suhu yang berbeda-beda. Masingmasing tipe akan di bagi dalam tiga kelompok perlakuan, untuk menguji specimen ini digunakan alat Impact Testing Machine, alat ini merupakan metode terbaik untuk menguji tumbukan pada bahan yang akan menghasilkan nilai kekuatan impact berdasarkan luas permukaan balok specimen akrilik. Kekuatan impact merupakan salah satu sifat yang dipengaruhi ketahanan 
terhadap fraktur dari basis gigi tiruan resin akrilik. Besarnya kekuatan impact dipengaruhi oleh kekuatan tarik dan modulus elastisitas.

Untuk pemanasan dengan suhu yang berbeda, setiap tipe bahan akrilik dibagi menjadi tiga kelompok pengujian, masing-masing kelompok terdiri dari 6 spesimen. Dalam setiap kelompok tipe akan dilakukan pemanasan pada suhu yang berbeda, kelompok satu dipanaskan pada suhu $100^{\circ} \mathrm{C}$, kelompok dua dipanaskan pada suhu $200^{\circ} \mathrm{C}$ dan kelompok tiga dipanaskan pada suhu $300^{\circ} \mathrm{C}$. Untuk polimerisasi panas resin akrilik, pencampurannya polimer dan monomer dengan perbandingan 3:1 berdasarkan volumenya atau 2:1 berdasarkan berat. Polimerisasi resin akrilik dipanaskan dalam suhu $70^{\circ} \mathrm{C}$ dipertahankan selama 30 menit, kemudian suhu dinaikan menjadi $100^{\circ} \mathrm{C}$ dan dipertahankan selama 90 menit, setelah itu perlahan-lahan diturunkan hingga dengan suhu ruangan (3). hal ini berbeda dengan resin akrilik sebelumnya yang memerlukan waktu sekitar 120 menit untuk proses polimerisasi.

\section{Hasil rata-rata pengujian :}

Tabel 1 Tabel hasil rata-rata charpy impact sampel akrilik

\begin{tabular}{lcc}
\hline Sample Marking & Nilai rata-rata $(\mathrm{kj} / \mathrm{m} 2)$ & Keterangan \\
\hline Tipe A suhu normal & 0,11 & 6 sampel \\
Tipe A suhu $100^{\circ} \mathrm{C}$ & 0,02 & 6 sampel \\
Tipe A suhu $200^{\circ} \mathrm{C}$ & 0,11 & 6 sampel \\
Tipe A suhu $300^{\circ} \mathrm{C}$ & 0,11 & 6 sampel \\
Tipe B suhu normal & 0,11 & 6 sampel \\
Tipe B suhu $100^{\circ} \mathrm{C}$ & 0,06 & 6 sampel \\
Tipe B suhu $200^{\circ} \mathrm{C}$ & 0,11 & 6 sampel \\
Tipe B suhu $300^{\circ} \mathrm{C}$ & 0,16 & 6 sampel \\
Tipe C suhu normal & 0,07 & 6 sampel \\
Tipe C suhu $100^{\circ} \mathrm{C}$ & 0,04 & 6 sampel \\
Tipe C suhu $200^{\circ} \mathrm{C}$ & 0,07 & 6 sampel \\
Tipe C suhu $300^{\circ} \mathrm{C}$ & 0,22 & 6 sampel \\
\hline
\end{tabular}

Sumber: Data penelitian laboratorium yang diolah 


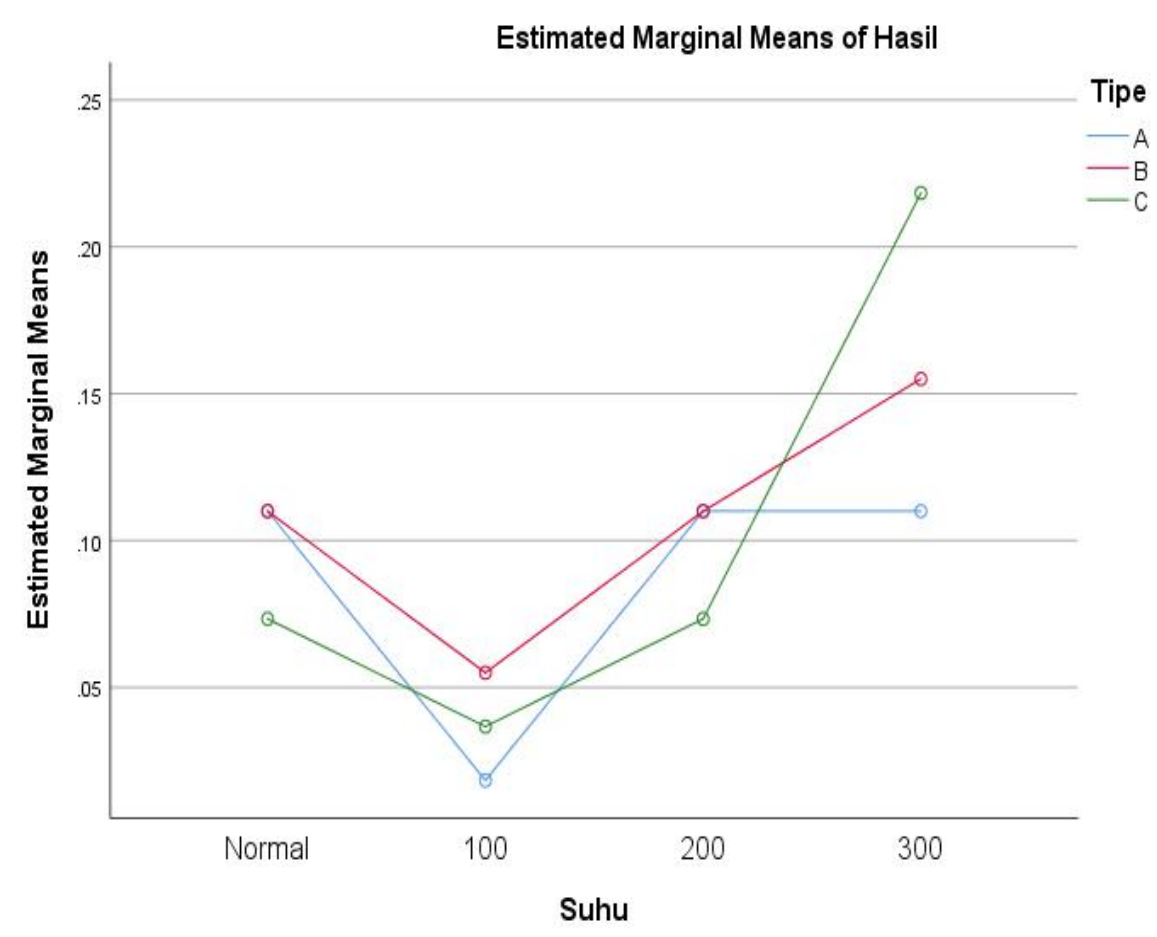

Grafik 1 hasil pengujian Charpy impact sample akrilik

Tabel 1 dan grafik 1 Memperlihatkan distribusi dan perbedaan nilai rata-rata hasil pengujian charpy impact sampel akrilik pada setiap kelompok sampel dan berbagai tipe dalam suhu yang berbeda. Pada grafik di atas terlihat distribusi setiap kelompok tipe suhu berbeda memperlihatkan nilai impact strength tertinggi dari ketiga kelompok tipe yang berbeda yaitu tipe $\mathrm{C}$ dengan nilai kekuatan impact $0,22(\mathrm{kj} / \mathrm{m} 2)$. Sedangkan tipe A pada pemanasan suhu dari $200^{\circ} \mathrm{C}$ ke suhu $300^{\circ} \mathrm{C}$ nilai impact strength-nya stabil. Sedangkan untuk tipe B dan C, dari suhu $200^{\circ} \mathrm{C}$ ke suhu $300^{\circ} \mathrm{C}$ nilai impact strength-nya terjadi peningkatan.

Pada hasil penelitian ini juga menunjukkan bahwa untuk perbandingan tipe $\mathrm{A}, \mathrm{B}$ dan $\mathrm{C}$ nilai sig $=0,711>0,05$, sehingga $\mathrm{H} 0$ tidak ditolak, yang berarti rata-rata hasil tidak berbeda nyata karena adanya perbedaan tipe. Kemudian melihat tabel selanjutnya untuk penambahan suhu setiap tipe Nilai sig $=0,001<0,05$, sehingga $\mathrm{H} 0$ ditolak, yang berarti rata-rata hasil berbeda nyata karena adanya perbedaan suhu. 
Untuk perbedaan tipe A, B dan $\mathrm{C}$ nilai sig $=0,711>0,05$, sehingga $\mathrm{H} 0$ tidak ditolak, yang berarti rata-rata hasil tidak berbeda nyata karena adanya perbedaan tipe. Rata-rata hasil tipe A, B dan C, masing-masing 0,087, 0,108 dan 0,100, dimana rata-rata ketiga tipe tersebut tidak berbeda signifikan. Perbedaan yang ada terjadi akibat pengambilan sampel, bukan perbedaan yang nyata secara statistik.

Selanjutnya untuk perbedaan suhu nilai sig $=0,001<0,05$ sehingga $\mathrm{H} 0$ ditolak, berarti rata-rata hasil berbeda nyata karena adanya perbedaan suhu. Berarti ada pengaruh penambahan suhu terhadap nilai impact strength. Hal ini berbanding terbalik dengan pendapat dari Suguh Bahtiar dkk (3) bahwa resin akrilik sensitif terhadap panas, kekerasannya pasti akan berkurang jika mengalami pemanasan yang berulang atau dipanaskan berlebihan.

\section{SIMPULAN}

Berdasarkan hasil penelitian ini didapatkan bahwa pengaruh penambahan suhu terhadap kekuatan permukaan basis gigi tiruan resin akrilik polimerisasi panas terdapat perbedaan kekuatan, semakin suhu ditingkatkan basis akrilik akan semakin kuat. Dapat disimpulkan bahwa ada pengaruh pemanasan dengan penambahan suhu terhadap impact strength resin akrilik tipe A, B dan C. Karena nilai sig $=0,001<0.05$ maka H0 ditolak, yang dapat diartikan bahwa rata-rata hasil berbeda nyata karena adanya perbedaan suhu.

Dengan demikian setiap tipe resin akrilik yang kami uji apabila dilakukan penambahan suhu dalam proses polimerisasi panas akan cenderung terjadi perubahan nilai kekuatan impact.

\section{UCAPAN TERIMA KASIH}

Penelitian ini dapat dilaksanakan dengan baik berkat bantuan dari berbagai pihak, untuk itu peneliti mengucapkan terima kasih kepada pihak yang mendukung proses penelitian terutama kepada pihak penyandang dana penelitian ini Poltekkes Jakarta II, para tim peneliti dan laboratorium uji penelitian yang terlibat dan membantu pada penyusunan penelitian ini.

\section{DAFTAR PUSTAKA}

1. Muluwere, V. O., Mariati, N. W. \& Wicaksono, D. A. Gambaran Pengetahuan Dan Status Kebersihan Mulut Pada Pemakai Gigi Tiruan Sebagai Lepasan Di Kelurahan Batu Kota Kecamatan Malalayang. e-GIGI3, (2015). 
2. Gigi, J. K. et al. Gambaran Pola Kehilangan Gigi Sebagian Pada Masyarakat Desa Guntung Ujung Kabupaten Banjar. II, 138-143 (2014).

3. Suguh Bhaktiar pribadi, Moh Yogiartono,Titien Hary Agustantina. Perubahan Kekuatan Impak resin akrilik Polimerisasi Panas Dalam Peremdaman laruatan Cuka Apel.2010.Dentofasial Jurnal Kedokteran Gigi Vol .9 No.1

4. Jatuadomi, ., Gunawan, P. N. \& Siagian, K. V. Alasan pemakaian gigi tiruan lepasan pada pasien poliklinik gigi di BLU RSUP Prof. Dr. R. D. Kandou Manado. e-GIGI4, 2-7 (2016).

5. Khoman, J. A., Mariati, N. W. \& Siagian, E. D. Profil Pemakaian Gigi Tiruan Lepasan Berbasis Akrilik Pada Masyarakat Kelurahan Bahu Kecamatan Malalayang. J. Biomedik4, 43-51 (2013).

6. Wahjuni, S. \& Ayu Mandanie, S. Journal of Vocational Health Studies FABRICATION OF COMBINED PROSTHESIS WITH CASTABLE. J. Vocat. Heal. Stud.01, 75-81 (2017).

7. Sundari, I., Sofya, P. A. \& Hanifa, M. Studi Kekuatan Fleksural Antara Resin Akrilik Heat Cured dan Termoplastik Nilon Setelah Direndam dalam Minuman Kopi Uleekareng (Coffea robusta). J. Syiah Kuala Dent. Soc.1, 51-58 (2016).

8. Anusavice J, K. Ilmu Bahan Kedokteran Gigi. (Penerbit Buku Kedokteran EGC, 2013).

9. Pribadi, S. B., Yogiartono, M. \& Agustantina, T. H. Perubahan kekuatan impak resin akrilik polimerisasi panas dalam perendaman larutan cuka apel. J. Dentomaxillofacial Sci.9, 13 (2010).

10. Salim, S. Various curing methods on transverse strength of acrylic resin. Dent. J. (Majalah Kedokt. Gigi)43, 40 (2010).

11. Diansari, V., Fitriyani, S. \& Haridhi, F, M. Studi Pelepasan Monomer Sisa Dari Resin Akrilik Heat Cured Setelah Perendaman Dalam Akuades. Cakradonya Dent J8, 1-76 (2016).

12. Dyah, I. \& Siti, S. Pengaruh Cara Pemrosesan Resin Akrilik Terhadap Sifat Fisik dan Mekanik. Lemb. Pengabdi. Masyarakat- Univ. Gajah Mada 19-23 (2005).

13. Yau, W. F. E., Cheng, Y. Y., Clark, R. K. F. \& Chow, T. W. Pressure and temperature changes in heat-cured acrylic resin during processing. Dent. Mater.18, 622-629 (2002)

14. Al-khafagy, M. T., Al-musawi, R. M. \& Aboudy, A. T. A.-. The Effect of Using Modified Flask on the Porosity of Processed Heat- Cure Acrylic Resin. Int. J. Sci. Basic Appl. Res.12, 189-197 (2013).

15. John, M. . \& Angus, W. W. G. Bahan Kedokteran Gigi. (Buku kedokteran EGC, 2011).

16. http://repository.unimus.ac.id/1378/3/BAB II.pdf. (diunduh 26-8-2019, 10:11). 